\title{
STOCHASTIC RESPONSE OF REINFORCED CONCRETE BUILDINGS USING HIGH DIMENSIONAL MODEL REPRESENTATION
}

Deepak Sahu ${ }^{1}$ Nishanth $\mathrm{M}^{2}$ Prateek Dhir ${ }^{3}$ Pradip Sarkar ${ }^{4}{ }^{\S}$ Robin Davis ${ }^{5}$ and Sujith Mangalathu ${ }^{6}$

${ }^{1} \mathrm{Ph} . \mathrm{D}$. Scholar, Department of Civil Engineering, National Institute of Technology Rourkela, India, 769008

Email: deepaksahu3269@gmail.com

${ }^{2}$ Former Graduate Student, Department of Civil Engineering, National Institute of Technology Rourkela, India, 769008

Email: nishanth089@gmail.com

${ }^{3} \mathrm{Ph} . \mathrm{D}$. Scholar, Department of Civil and Environmental Engineering, University of Strathclyde Glasgow, UK

Email: prateek.dhir@strath.ac.uk

${ }^{4}$ Associate Professor, Department of Civil Engineering, National Institute of Technology Rourkela, India, 769008

Email: sarkarp@ nitrkl.ac.in

${ }^{5}$ Assisstant Professor, Department of Civil Engineering, National Institute of Technology Rourkela, India, 769008

Email: robin.davisp@gmail.com

${ }^{6}$ Post Doc Research Fellow, School of Civil and Environmental Engineering, University of California, Los Angels, CA90095, USA

Email: sujithmangalath@ucla.edu

${ }^{\S}$ Corresponding author 


\title{
STOCHASTIC RESPONSE OF REINFORCED CONCRETE BUILDINGS USING HIGH DIMENSIONAL MODEL REPRESENTATION
}

\author{
Deepak Sahu ${ }^{1}$ Nishanth $\mathrm{M}^{2}$ Prateek Dhir $^{3}$ Pradip Sarkar $^{4}$ Robin Davis ${ }^{5}$ and Sujith Mangalathu ${ }^{6}$
}

\begin{abstract}
Dynamic responses of structures are random in nature due to the uncertainties in geometry, material properties, and loading. The random dynamic responses can be represented fairly well by stochastic analysis. The methods used for stochastic analysis can be grouped into statistical and non-statistical approaches. Although statistical approaches like Monte Carlo simulation is considered as an accurate method for the stochastic analysis, computationally less intensive yet efficient, simplified non-statistical methods are necessary as an alternative. The present study is an evaluation of a relatively new non-statistical metamodel-based approach known as, High Dimensional Model Representation, with reference to existing response surface methods such as Central Composite Design, Box Behnken Design, and Full Factorial Design, in a dynamic response analysis. The geometry of a reinforced concrete frame is chosen to conduct free vibration and nonlinear dynamic analysis to study the stochastic responses using High Dimensional Model Representation method. This method was found to provide results as good as other methods with less computational effort with regard to the selected case studies.
\end{abstract}

Keywords: RC buildings, stochastic analysis, HDMR, RSM, free-vibration, seismic fragility 


\section{INTRODUCTION}

Structural behavior cannot be predicted deterministically in the case of disastrous loadings such as earthquakes, blasts, tsunamis, and hurricanes, where there is uncertainty associated with both the loading and structural resistance [1]. The structural responses associated with these disastrous events can be predicted in a probabilistic manner using a stochastic approach. This approach can account for the uncertainties associated with the loading and structural response. The stochastic approaches can be classified into two categories: statistical approaches and nonstatistical approaches. Monte Carlo Simulation (MCS) [2], Latin Hypercube Sampling (LHS) [3] and Stratified Sampling [4] are some of the commonly used statistical approaches [5]. MCS is a powerful technique which consists of repeated sampling process to obtain the responses but becomes computationally expensive [6] for problems having small probabilities.

In the case of non-statistical approaches, the responses are determined at selected sampling points, and a functional relationship is generated between the input and output variables [5, 7]. This functional relationship is usually known as a metamodel. Response surface method (RSM) [8] is the most widely used non-statistical approach. The selection of sampling points for the functional evaluation of the responses can be done by different techniques for design of experiments (DOE) such as Central Composite Design, (CCD) [9], Box-Behnken Design, BBD [10] and Factorial Designs (for example full factorial design, FFD [7]). CCD has been used in conjunction with metamodel for RSM by various studies such as time-invariant reliability of reinforced concrete (RC) frames [11], seismic fragilities of RC frames [12], seismic fragilities of irregular steel frames [13] and seismic fragilities of railway bridges $[14,15]$.

A high dimensional model representation (HDMR) [16] is an emerging method of stochastic analysis to represent the response surface in terms of a metamodel. It has been applied recently for the studies of structural behavior [17] and seismic fragilities [18]. However, its application has not yet been fully explored in the problems involving stochastic seismic response analysis in the context of other response surface methods, such as CCD, BBD, and FFD.

The objective of this paper is to investigate the effectiveness of the relatively new HDMR method, to problems involving free vibration analysis, nonlinear dynamic response analysis and fragility analysis of RC buildings, with reference to established response surface methods. 


\section{REVIEW OF METAMODEL BASED APPROACHES}

The present study considers two problems for stochastic analysis. The first problem is to obtain the random natural frequency and the second one is to predict the random nonlinear seismic response of a RC symmetric bare framed building. Stochastic analysis of the selected problems requires the evaluation of metamodel functions of HDMR, and RSM using different sampling techniques such as $\mathrm{CCD}, \mathrm{BBD}$, and FFD. This section provides a review of the above methods.

\subsection{RSM based on DOE approaches}

The response surface metamodel can be represented by its general form as shown in Eq. (1)

$$
y=f\left(x_{i}\right)+\varepsilon
$$

Here, $y$ represents the response (output), $x_{i}$ represents the input variables, and $\varepsilon$ represents the error in estimation. The error term can be neglected in the case of computer analysis [19]. The response surface input variables are the parameters whose uncertainty or randomness can cause an uncertainty in the output or response. The response can be modelled by a polynomial function. For a linear system, the first order polynomial can be used, whereas polynomials of higher orders are required to represent the system with curvature [20]. A second-order (quadratic) function proposed by Towashiraporn [19] is selected in the present study to represent the response. The form of such a function is shown in Eq. (2).

$$
y=\beta_{0}+\sum_{i=1}^{k} \beta_{i} x_{i}+\sum_{i=1}^{k} \beta_{i i} x_{i}^{2}+\sum_{i=1}^{k-1} \sum_{j=1}^{k} \beta_{i j} x_{i} x_{j}
$$

where $\beta$ is unknown coefficients or constants, and $k$ is the total number of input variables. To determine the unknown constants $(\beta)$, the design of experiment should be carried out at the chosen sampling points to obtain the response. The unknown constants in the polynomials can be estimated with the specific set of variables to obtain the metamodel. Thus, the functional relationship is established between the random input parameters and output responses.

The specific input values at the sampling or design points for the metamodel formulation are usually determined by DOE. Depending on the type of polynomial function selected, a variety of DOE can be used. Each method gives a different combination of the input variables. The 
different design or sampling methods adopted in this work are CCD, BBD, and FFD. Details on the various DOE sampling methods can be found in the literature [20, 21].

\subsection{HDMR based RSM metamodel approach}

HDMR method is used for the representation of input-output relationships, which are complex in nature and involves a considerable amount of computations. Such a model can be used to epitomize probability analysis of a system which needs a large computational cost and effort. In other words, tedious processes like the MCS can be carried out on this compact model effectively and efficiently [18].

The input variables and the output function in HDMR can be conveniently represented as the $N$-dimensional vector $x=\left\{x_{1}, x_{2}, \ldots x_{N}\right\}$ and $f(x)$ respectively. The value of $N$ can vary up to the order of 100-1000 or more. Similar to other response surface methods, the effect of input variables on the output function can be independent and/or correlated. These effects can be incorporated in the expression for output by considering the terms of higher order for the input variables. HDMR expresses the output $f(x)$ as a hierarchical correlated function expansion in terms of the input variables as in Eq. (3).

$$
f(x)=f_{0}+\sum_{i=1}^{N} f_{i}\left(x_{i}\right)+\sum_{1<i_{1}<i_{2}<N} f_{i_{1} i_{2}}\left(x_{i_{1}}, x_{i_{2}}\right)+\sum_{1<i_{1}<i_{2}<i_{3}<N} f_{i_{1} i_{2} i_{3}}\left(x_{i_{1}}, x_{i_{2}}, x_{i_{3}}\right)+\ldots \ldots+f_{i_{1} i_{2} \ldots \ldots i_{N}}\left(x_{i_{1}}, x_{i_{2}}, \ldots \ldots . x_{i_{N}}\right)
$$

where, $f_{0}$ is the constant obtained by the response $f(x)$ at a selected reference point (mean point), $f_{i}\left(x_{i}\right)$ is the first order term representing the individual contribution of the variable $x_{i}$ on the output, $f_{i_{1} i_{2}}$ is the second order term for the co-operative effects of the variables $x_{i_{1}}$ and $x_{i_{2}}$ on the output, $f_{i_{1} i_{2} \ldots i_{N}}\left(x_{i_{1}}, x_{i_{2}}, \ldots x_{i_{N}}\right)$ is the residual dependence of all the input variables that influence the output $f(x)$. The functions of HDMR metamodel expressed in Eq. (3) can be determined by any suitable method. In the present study, finite element analysis (FEA) of the structure is carried out at the reference points $c=\left\{c_{1}, c_{2}, c_{3}, c_{N}\right\}$ consisting of the mean values of the selected variables and the component functions of the Eq. (3) are reduced as:

$$
f_{0}=f(c)
$$




$$
\begin{aligned}
& f_{i}\left(x_{i}\right)=f\left(x_{i}, c^{i}\right)-f_{0} \\
& f_{i_{1} i_{2}}\left(x_{i_{1}}, x_{i_{2}}\right)=f\left(x_{i_{1}}, x_{i_{2}}, c^{i_{1} i_{2}}\right)-f_{i_{1}}\left(x_{i_{1}}\right)-f_{i_{2}}\left(x_{i_{2}}\right)-f_{0}
\end{aligned}
$$

In Eq. (5), $f\left(x_{i}, c^{i}\right)=f\left(c_{1}, c_{2}, \ldots, c_{i-1}, x_{i}, c_{i+1}, \ldots c_{N}\right)$ represents the response of the structure when all the input variables except $x_{i}$ are at their mean points, similarly the function $f\left(x_{i_{1}}, x_{i_{2}}, c_{i_{1}}, c_{i_{2}}\right)=f\left(c_{1}, c_{2}, \ldots c_{i_{1}-1}, x_{i_{1}}, c_{i_{1}+1}, \ldots c_{i_{2}-1}, x_{i_{2}}, c_{i_{2}+1}, \ldots, c_{N}\right)$ indicate that the random variables except $\left(x_{i_{1}}, x_{i_{2}}\right)$ are at their reference or mean values. The value $f_{0}$ is obtained as the output when all the random variables are at their mean values, $c=\left\{c_{1}, c_{2}, c_{3}, c_{N}\right\}$. The higher order terms are evaluated as per standard methods in the input variable space around the reference point. The lower order expansion functions are subtracted off to remove the dependency.

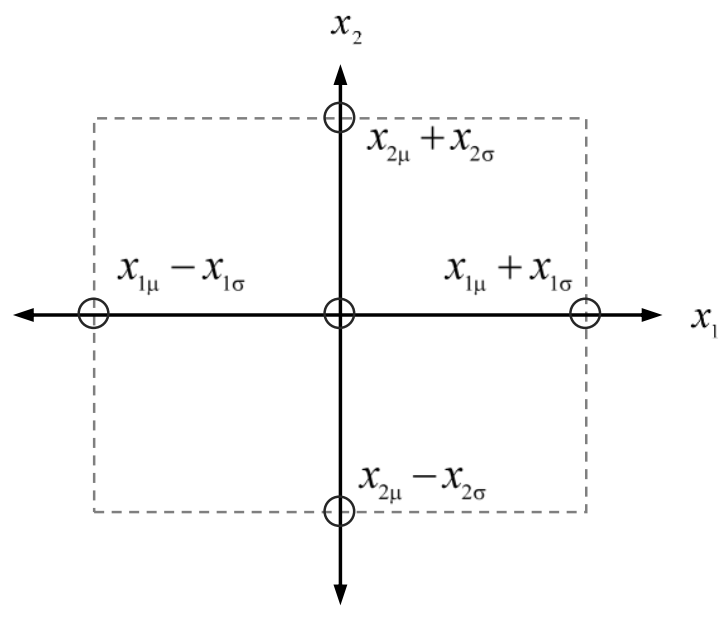

Figure 1. Two-dimensional schematic representation of sampling in HDMR.

A three-point sampling is used in the current study for the development of HDMR metamodel. The sampling process using three-point sampling method for two $(n=2)$ random parameters, $x_{1}$ and $x_{2}$ is explained in Fig. 1. The horizontal and vertical axis represents the random parameters $x_{1}$ and $x_{2}$ respectively. The sampling points to be considered are represented by grid points. There are five grid points $(2 n+1=5)$ for the two random parameters, $x_{1}$ and $x_{2}$. The center sampling point at $\left(x_{1}, x_{2}\right)$ is represented by mean values of parameter $x_{1}$ and $x_{2}$. When a parameter $x_{1}$ is considered, two sampling points, $\left(x_{1 \mu}+x_{1 \sigma}, x_{2 \mu}\right)$ and $\left(x_{1 \mu}-x_{1 \sigma}, x_{2 \mu}\right)$ on either side of mean of $x_{1}$ shall also be 
considered. Similarly, three sampling points (with a common center point) are to be considered for the random variable, $x_{2}$. The output value at the five sampling points is required to solve the five constants of the metamodel function involving two random variables. When there is higher number of random variables, the grid will have that many dimensions in space.

\section{DESCRIPTION OF THE STRUCTURE}

An RC frame with four storeys and two bays in both of the two horizontal directions is selected for the present study as shown in Fig 2. Bay width and column height in this study are taken uniformly as $5 \mathrm{~m}$ and $3.2 \mathrm{~m}$ respectively. The building geometry is adopted from published literature [22]. The building frame is designed for the highest seismic zone of India (Zone V with PGA of $0.36 \mathrm{~g}$ ) as per relevant Indian standards [23, 24, 25] considering medium soil conditions $(\mathrm{N}$-value in the range 10 to 30$)$.

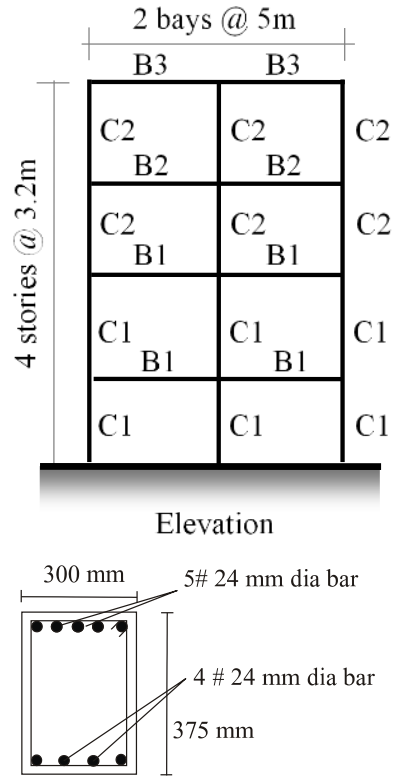

B1

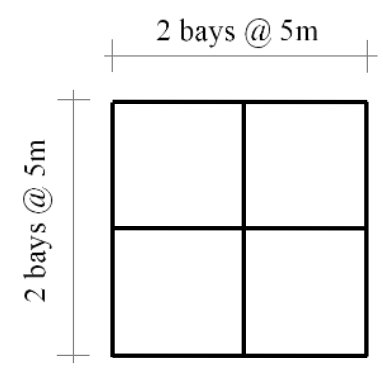

Typical floor plan

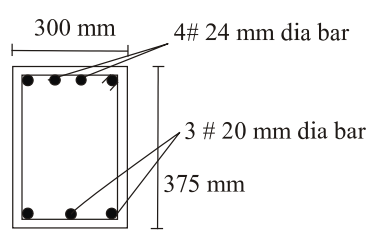

B2
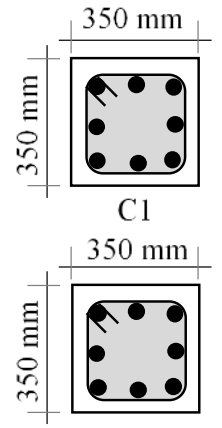

$\mathrm{C} 2$

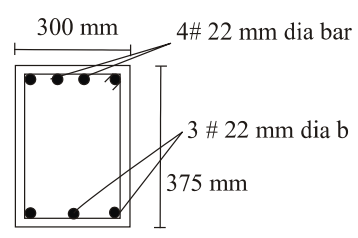

B3

Figure 2. Details of the selected building with mean values of dimensions.

The mean values of the characteristic strength of concrete in compression and reinforcement steel are taken as $25 \mathrm{MPa}$ and $415 \mathrm{MPa}$, respectively for design. The mean value of storey weight including an appropriate portion of the live load is calculated to be about $700 \mathrm{kN}$ which is considered uniformly for all storeys. The column ends are assumed to be fixed at the support. 
Selected frame is modelled for (i) elastic free vibration analysis and (ii) nonlinear time history analysis. Open System for Earthquake Engineering Simulation (OpenSees) Laboratory tool [26] is used for all the above analyses. The force-based nonlinear beam-column element that considers the spread of plasticity along the element is used for modelling the beams and columns for nonlinear time history analyses. The confined core and unconfined cover concrete section are modelled using the Kent and Park material model [27]. Steel reinforcing bars are modelled using uniaxial Giuffre-Menegotto-Pinto steel material model [28] with isotropic strain hardening of $1.5 \%$. The in-plane stiffness of the floor is modelled using rigid diaphragm constraint. The beam column joints are assumed to be rigid.

\section{FREE VIBRATION RESPONSE OF RC FRAME}

The fundamental natural frequency of a building is an important response parameter for its dynamic behavior. The fundamental frequency is uncertain in reality due to the possible uncertainties in the geometry and elastic material properties of the structure. Stochastic free vibration analysis of selected RC building frame using non-statistical (metamodel based) methods (HDMR, CCD, BBD, and FFD) is conducted to verify the accuracy of the results with reference to statistical (MCS and LHS) methods and presented in this section.

\subsection{Modelling of uncertainties}

The following material and geometrical parameters selected from the previous studies [29-42] are considered as input random variables to model the uncertainties in the structure: modulus of elasticity of concrete $\left(E_{c}\right)$, storey weight $(W)$, storey height $(h)$, beam depth $\left(B_{d}\right)$, beam width $\left(B_{w}\right)$, column depth $\left(C_{d}\right)$, and column width $\left(C_{w}\right)$. The statistical details for each of the selected random variables are shown in Table 1 . The $\mathrm{COV}$ of the random variable, $W$, is taken as $10 \%$ considering different previous literature $[43,44,45]$. It is to be noted here that some of the data associated with the statistical details presented in Table 1 relies on local data, which may or may not be proper for general consideration. 


\subsection{Development of metamodel using HDMR}

The random output variable, fundamental natural frequency $(\omega)$ of the selected frame is represented as a function of all the input random variables (given in Table 1). In order to construct the metamodel, the computational model of the frame is generated at selected sampling points of the input parameters to conduct the free vibration analysis. The values of the seven random variables obtained at the sampling points (refer to Fig 1) are presented in Table 2.

Table 1. Statistical details of random variables

\begin{tabular}{|c|l|c|c|l|c|}
\hline $\begin{array}{c}\text { Sl. } \\
\text { No }\end{array}$ & \multicolumn{1}{|c|}{ Property } & \multicolumn{1}{|c|}{ Mean } & COV $(\%)$ & $\begin{array}{l}\text { Probability } \\
\text { Distribution }\end{array}$ & Source \\
\hline 1 & Modulus of elasticity $\left(E_{c}\right)$ & $29 \mathrm{kN} / \mathrm{mm}^{2}$ & 15 & Lognormal & {$[38]$} \\
\hline 2 & Storey Weight $(W)$ & $700 \mathrm{kN}$ & 10 & Normal & {$[43,44,45]$} \\
\hline 3 & Storey Height $(h)$ & $3200 \mathrm{~mm}$ & 8 & Lognormal & {$[46]$} \\
\hline 4 & Beam Depth $\left(B_{d}\right)$ & $350 \mathrm{~mm}$ & 1.5 & Normal & {$[42]$} \\
\hline 5 & Beam Width $\left(B_{w}\right)$ & $300 \mathrm{~mm}$ & 3 & Normal & {$[42]$} \\
\hline 6 & Column Depth $\left(C_{d}\right)$ & $400 \mathrm{~mm}$ & 1.5 & Normal & {$[42]$} \\
\hline 7 & Column Width $\left(C_{w}\right)$ & $400 \mathrm{~mm}$ & 3 & Normal & {$[42]$} \\
\hline
\end{tabular}

Table 2. Values of input variables obtained by 3-point sampling for HDMR

\begin{tabular}{|c|c|c|c|c|}
\hline Variable & Unit & $\mu-\sigma$ & $\mu$ & $\mu+\sigma$ \\
\hline$E_{c}$ & $\mathrm{kN} / \mathrm{mm}^{2}$ & 24.65 & 29.00 & 33.35 \\
\hline$W$ & $\mathrm{kN}$ & 630 & 700 & 770 \\
\hline$h$ & $\mathrm{~mm}$ & 2944 & 3200 & 3456 \\
\hline$B_{d}$ & $\mathrm{~mm}$ & 369.37 & 375.00 & 380.62 \\
\hline$B_{w}$ & $\mathrm{~mm}$ & 291 & 300 & 309 \\
\hline$C_{d}$ & $\mathrm{~mm}$ & 344.75 & 350.00 & 355.25 \\
\hline$C_{w}$ & $\mathrm{~mm}$ & 339.50 & 350.00 & 360.50 \\
\hline
\end{tabular}

( $\mu$ and $\sigma$ are mean and standard deviation of the random variables) 
The metamodel representing random fundamental frequency of the frame $(\omega)$ using HDMR method can be obtained from Eq. (3) as follows:

$$
\omega=f_{0}+f\left(E_{c}\right)+f\left(w_{L}\right)+f(h)+f\left(B_{4}\right)+f\left(B_{w}\right)+f\left(C_{4}\right)+f\left(C_{w}\right)
$$

The functions $f\left(E_{c}\right), f\left(w_{L}\right), f(h), f\left(B_{d}\right), f\left(B_{w}\right), f\left(C_{d}\right)$ and $f\left(C_{w}\right)$ in Eq. (7) are assumed as second-order functions of the respective random variables as,

$$
f(z)=a_{0}+a_{1} z+a_{2} z^{2}
$$

The coefficients $a_{0}, a_{1}$ and $a_{2}$ are established by taking the input-output combinations of the three sampling points where all the random variables, except the considered random variable $(z)$ are at their mean values.

Table 3. Comparison of fundamental frequencies at sampling points

\begin{tabular}{|c|c|c|c|c|c|c|c|c|c|}
\hline $\begin{array}{c}\text { Sl. } \\
\text { No }\end{array}$ & $\begin{array}{c}E_{c} \\
\left(\mathrm{kN} / \mathrm{mm}^{2}\right)\end{array}$ & $W(\mathrm{kN})$ & $\begin{array}{c}h \\
(\mathrm{~mm})\end{array}$ & $\begin{array}{c}B_{d} \\
(\mathrm{~mm})\end{array}$ & $\begin{array}{c}B_{w} \\
(\mathrm{~mm})\end{array}$ & $\begin{array}{c}C_{d} \\
(\mathrm{~mm})\end{array}$ & $\begin{array}{c}C_{w} \\
(\mathrm{~mm})\end{array}$ & $\begin{array}{c}\text { Calculated } \\
\text { using FEA }\end{array}$ & $\begin{array}{c}\text { Predicted } \\
\text { from } \\
\text { Metamodel }\end{array}$ \\
\hline 1 & 29 & 700 & 3200 & 375 & 300 & 350 & 350 & 1.441 & 1.441 \\
\hline 2 & 24.65 & 700 & 3200 & 375 & 300 & 350 & 350 & 1.328 & 1.328 \\
\hline 3 & 33.35 & 700 & 3200 & 375 & 300 & 350 & 350 & 1.545 & 1.545 \\
\hline 4 & 29 & 630 & 3200 & 375 & 300 & 350 & 350 & 1.489 & 1.489 \\
\hline 5 & 29 & 770 & 3200 & 375 & 300 & 350 & 350 & 1.397 & 1.397 \\
\hline 6 & 29 & 700 & 2944 & 375 & 300 & 350 & 350 & 1.603 & 1.603 \\
\hline 7 & 29 & 700 & 3456 & 375 & 300 & 350 & 350 & 1.305 & 1.305 \\
\hline 8 & 29 & 700 & 3200 & 369.375 & 300 & 350 & 350 & 1.426 & 1.426 \\
\hline 9 & 29 & 700 & 3200 & 380.625 & 300 & 350 & 350 & 1.455 & 1.455 \\
\hline 10 & 29 & 700 & 3200 & 375 & 291 & 350 & 350 & 1.435 & 1.435 \\
\hline 11 & 29 & 700 & 3200 & 375 & 309 & 350 & 350 & 1.447 & 1.447 \\
\hline 12 & 29 & 700 & 3200 & 375 & 300 & 344.75 & 350 & 1.437 & 1.437 \\
\hline 13 & 29 & 700 & 3200 & 375 & 300 & 355.25 & 350 & 1.454 & 1.454 \\
\hline 14 & 29 & 700 & 3200 & 375 & 300 & 350 & 339.5 & 1.433 & 1.433 \\
\hline 15 & 29 & 700 & 3200 & 375 & 300 & 350 & 360.5 & 1.468 & 1.468 \\
\hline
\end{tabular}

The number of sampling points required in the HDMR method depends on the number of random variables chosen in the problem. For the three-point sampling method, it requires about 
three equations to evaluate the three coefficients $\left(a_{0}, a_{1}\right.$ and $\left.a_{2}\right)$ for each random variable. For the seven $(n=7)$ random variables taken here, the number of sampling points is $(2 n+1=15)$ fifteen. Therefore, the number of FEA required for the solution of unknown coefficients are also fifteen. The fifteen equations are solved to obtain the unknown coefficients that define the metamodel. The output fundamental frequencies at each sampling points are predicted from developed metamodel using HDMR. Table 3 compares the fundamental frequencies obtained from FEA with those predicted using HDMR.

The coefficients computed for each random variable for the formation of overall metamodel are presented in Table 4. It can be seen that the coefficients $a_{1}$ and $a_{2}$ representing the metamodel for the random variables, $E_{\mathrm{c}}$ and $W$ are found to be small (with reference to that of other variables). This means that the sensitivity of these parameters on the frequency of the frame is less compared to that of other random variables. Hence, neglecting these parameters may not affect the output frequency significantly.

Table 4. Metamodel coefficients obtained for HDMR.

\begin{tabular}{|c|c|c|c|c|c|c|c|}
\hline $\begin{array}{c}\text { Coeffi } \\
\text { cients }\end{array}$ & $E_{c}$ & $W$ & $h$ & $B_{d}$ & $B_{w}$ & $C_{d}$ & $C_{w}$ \\
\hline$a_{0}$ & -0.904 & 0.685 & 3.902 & -1.713 & -0.411 & 20.949 & 9.962 \\
\hline$a_{1}$ & $3.74 \mathrm{E}-02$ & $-1.30 \mathrm{E}+05$ & $-1.86 \mathrm{E}-03$ & $6.56 \mathrm{E}-03$ & $2.07 \mathrm{E}-03$ & $-1.21 \mathrm{E}-01$ & $-5.86 \mathrm{E}-02$ \\
\hline$a_{2}$ & $-2.16 \mathrm{E}-04$ & $4.53 \mathrm{E}+09$ & $1.99 \mathrm{E}-07$ & $-5.31 \mathrm{E}-06$ & $-2.35 \mathrm{E}-06$ & $1.76 \mathrm{E}-04$ & $8.61 \mathrm{E}-05$ \\
\hline
\end{tabular}

To evaluate the accuracy of the metamodel expressions, the frequencies at the sampling points obtained from FEA and metamodel are plotted graphically and presented in Fig. 3 for various selected metamodels. The evaluation of unknown coefficients representing the HDMR metamodel involves the solution of simultaneous equations having a number of variables equal to the number of unknowns. The other metamodel methods, CCD, BBD, and FFD, involve minimization of error to evaluate the unknown coefficients. Due to this reason the $\mathrm{R}^{2}$ values observed for the methods, CCD, BBD, and FFD are not exactly unity, while that for HDMR it is exactly unity. 


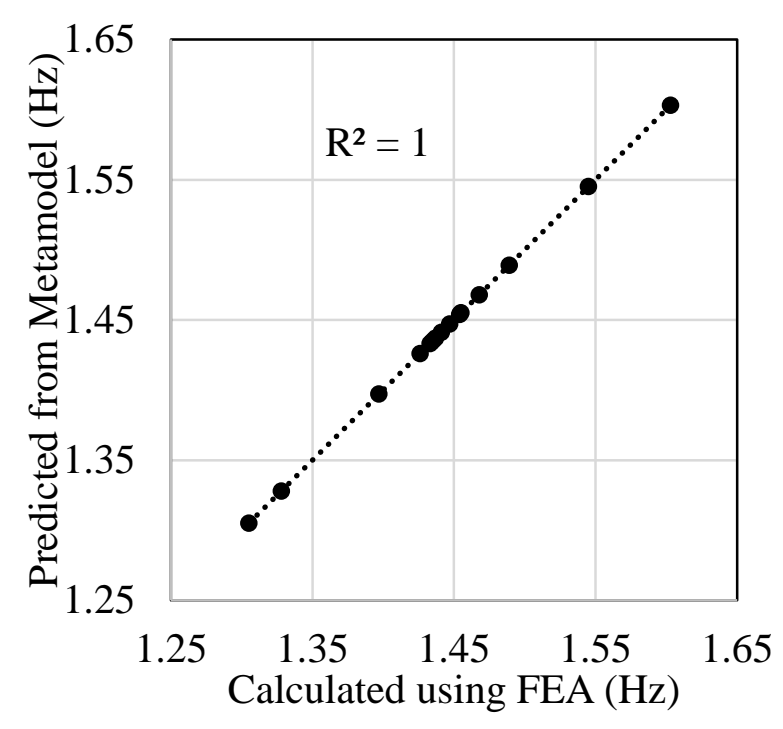

(a) HDMR

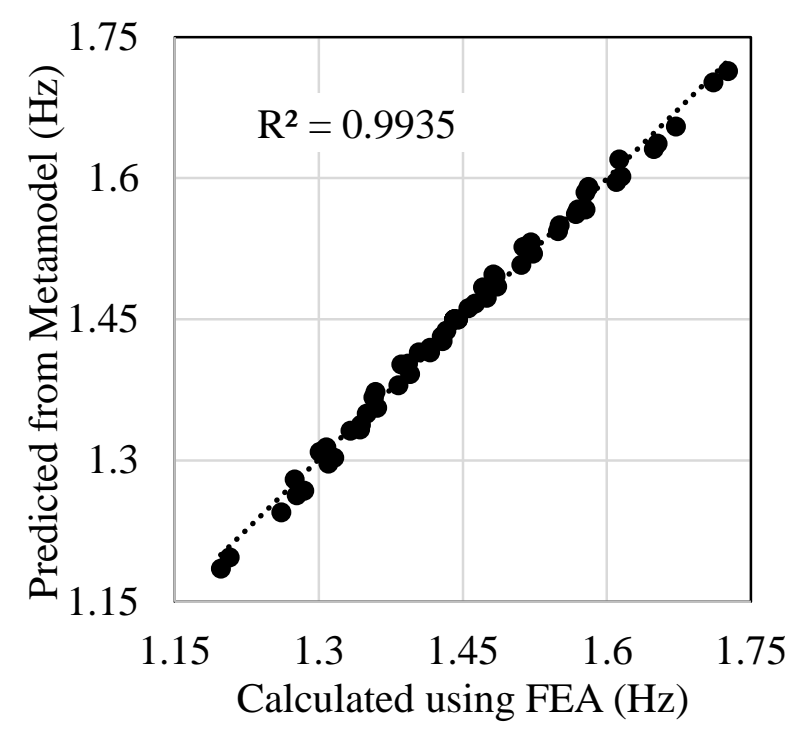

(c) $\mathrm{BBD}$

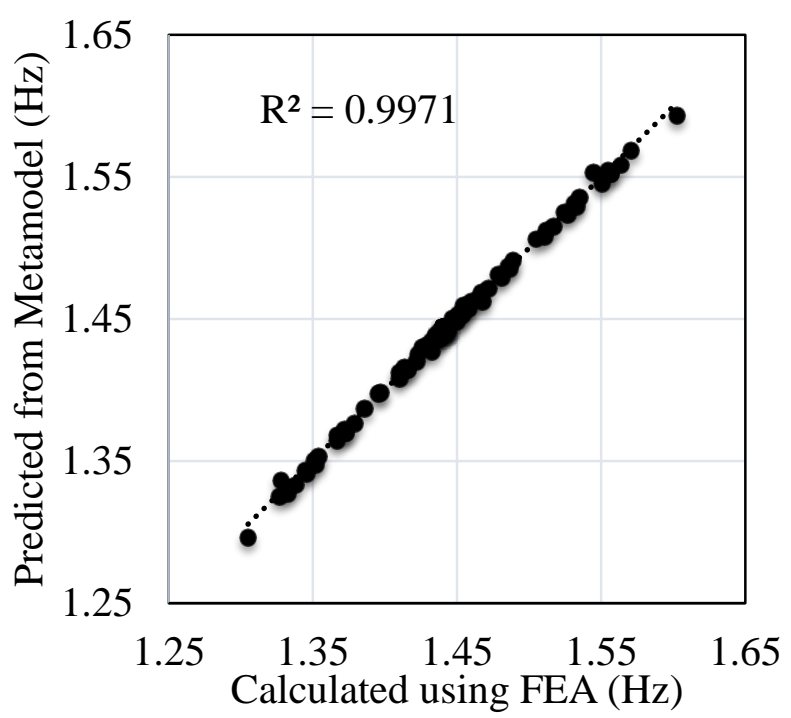

(b) $\mathrm{CCD}$

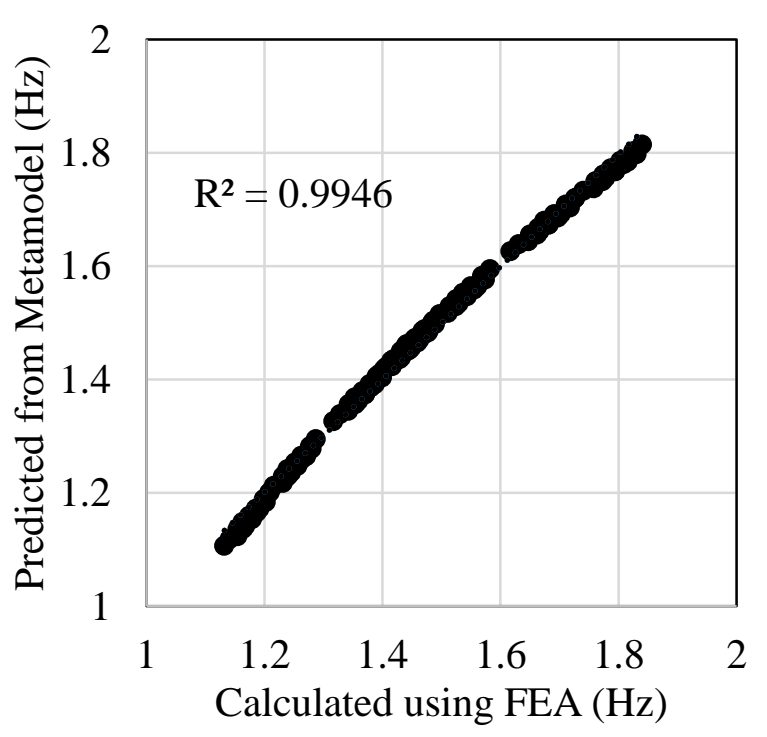

(d) FFD

Figure 3. Comparison of natural frequency responses at sampling points obtained from FEA and metamodel methods.

\subsection{Comparison of the performance of HDMR with other methods}

The stochastic fundamental frequencies of the frame are obtained as per various metamodel expressions (HDMR, CCD, BBD, and FFD) using the values of random input variables $\left(E_{c}, W, h\right.$, 
$\left.B_{d}, B_{w}, C_{d}, C_{w}\right)$ generated considering their statistical properties. It is to be noted that once the metamodel is formulated, it can be used for simulations of output frequencies without the need of further FEA. Each simulations using the metamodel can be done with the less computational effort by eliminating the FEA.

However, to have a reasonably accurate estimation of the output frequency, a minimum number of simulations shall be conducted on the metamodel. A convergence study is conducted considering the mean frequency response by varying the number of simulations of metamodel from 10 to 100,000 . The variation of the mean frequency versus the number of simulations obtained for all the metamodel methods is plotted in the Fig. 4. The MCS is also conducted for a various number of samples of the same range as a reference. It can be seen that the mean frequency is converged to a stable value corresponding to the number of simulations of 100,000 for all the methods. Hence, 100,000 simulations are conducted for further studies. The number of simulations that yield convergence can only be valid for the demand parameters used in the study. This number may change for other demand parameters.

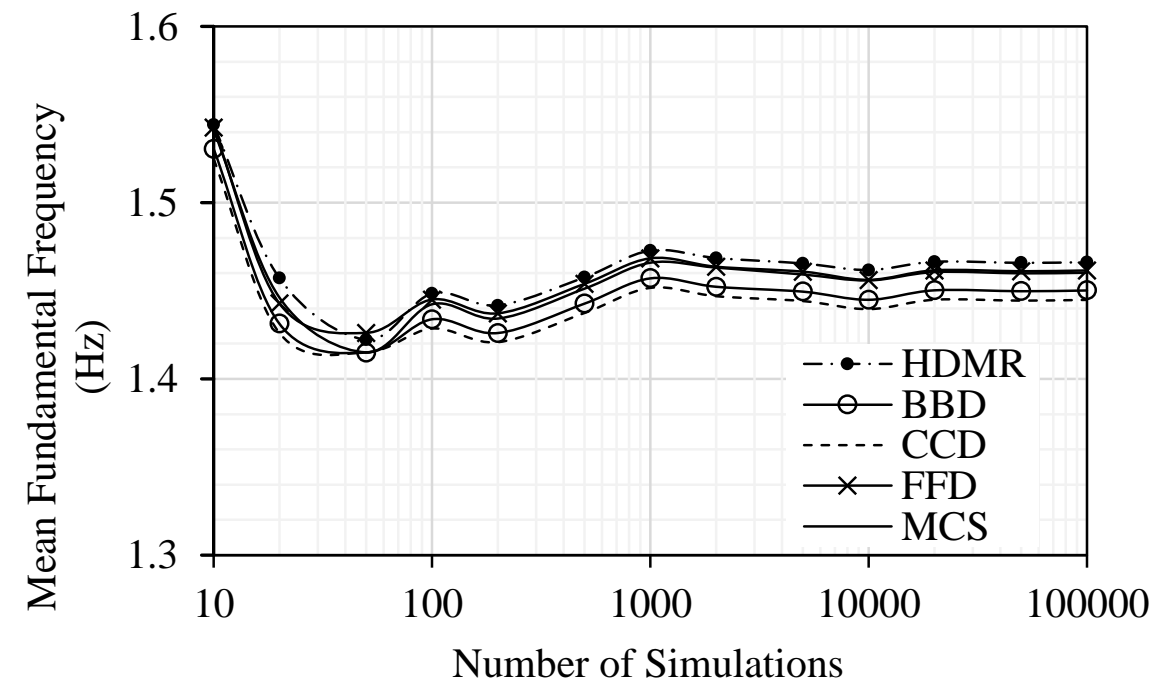

Figure 4. Convergence of mean fundamental frequency from different metamodel methods.

The effectiveness of each metamodel method is studied from the mean and standard deviation of the output frequency responses obtained as well as the number of FEA required to establish the metamodel. These results are summarized in Table 5. It shows that the HDMR method requires the lowest number of FEA (i.e., 15) compared to the other methods to build the 
metamodel. The mean frequencies and associated standard deviations are calculated using each metamodel method considering 100,000 different set of input values. Results are also obtained from MCS and LHS methods for reference. The same set of 100,000 input values are used for the MCS method. LHS results are obtained for two different number of input variable set: 15 (LHS 15) set of input variables to check the performance of HDMR as it required 15 number of finite element analyses and 100 (LHS - 100) set of input variables for better accuracy.

Table 5 shows that mean frequency results of both HDMR and FFD metamodels are in close agreement with MCS results (with less than $0.5 \%$ error). In the case of CCD and BBD, the error reaches up to $1 \%$. However, considering that the HDMR requires the lowest number of FEA to generate the metamodel, it can be concluded that the performance of HDMR is better than the other metamodel methods. Table 5 shows that the accuracy of the results is found to be marginally affected by the sample size chosen for the LHS. The error in the estimate of the mean for a sample size of 15 is found to be negligible compared to that of a sample size of 100. Table 5 also shows the effectiveness of LHS method over the MCS method as LHS method with sample size of 100 predicts mean frequencies with a similar accuracy of MCS with sample size of 100,000.

Table 5. Statistical parameters of natural frequency obtained from different methods

\begin{tabular}{|c|c|c|c|}
\hline Methods & Mean $(\mathrm{Hz})$ & Std. Dev. (Hz) & $\begin{array}{c}\text { No. of samples } \\
\text { required to create } \\
\text { metamodels }\end{array}$ \\
\hline HDMR & 1.466 & 0.190 & 15 \\
\hline CCD & 1.446 & 0.191 & 100 \\
\hline BBD & 1.450 & 0.192 & 62 \\
\hline FFD & 1.461 & 0.193 & 128 \\
\hline MCS - 100,000 & 1.460 & 0.193 & - \\
\hline LHS - 15 & 1.465 & 0.190 & - \\
\hline LHS - 100 & 1.459 & 0.192 & - \\
\hline
\end{tabular}

The fundamental frequency responses obtained from all the metamodel methods, HDMR, $\mathrm{CCD}, \mathrm{BBD}$, and FFD, are compared with the corresponding values obtained by MCS in Figs. 5a, $5 b, 5 c$, and $5 d$ respectively. It can be seen that the HDMR method performs better compared to 
other metamodel methods as evident from the $\mathrm{R}^{2}$ values. Fig. 6 shows the comparison of probability distributions of output fundamental frequencies simulated by various metamodel approaches along with MCS and LHS - 100 methods. The statistical difference between the probability distributions of natural frequencies obtained by the various methods is found to be negligible, and the frequencies are found to be normally distributed.

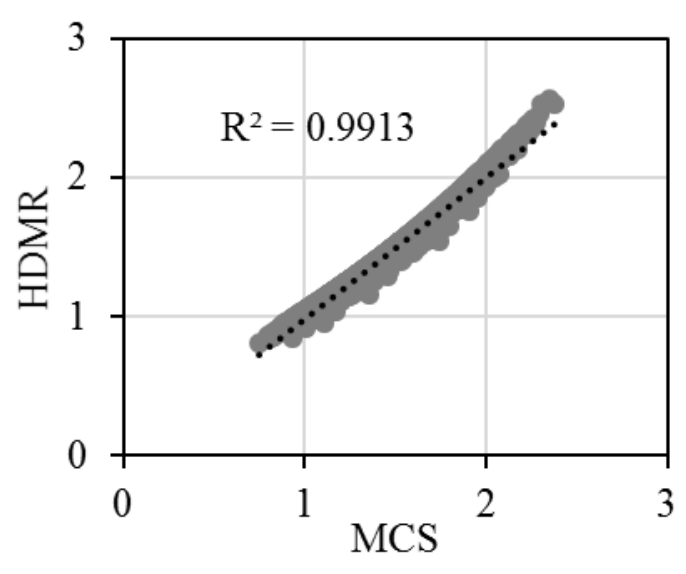

(a) HDMR

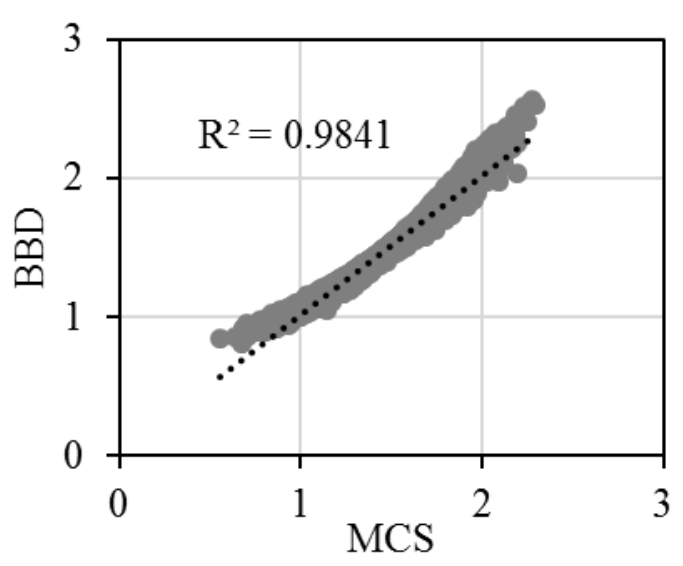

(c) BBD

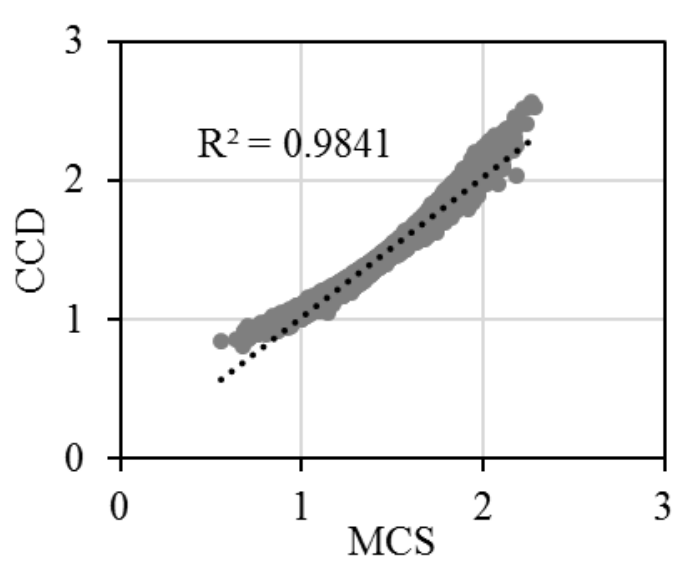

(b) $\mathrm{CCD}$

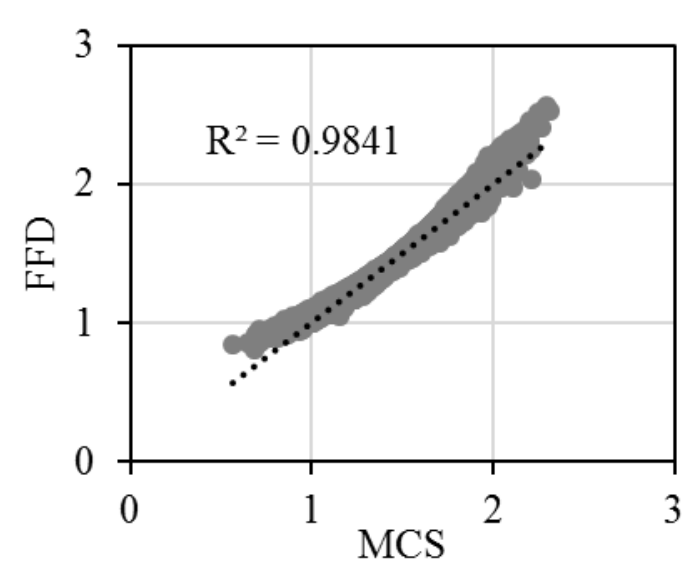

(d) FFD

Figure 5. Comparison of fundamental frequencies $(\mathrm{Hz})$ predicted by metamodel methods with MCS 


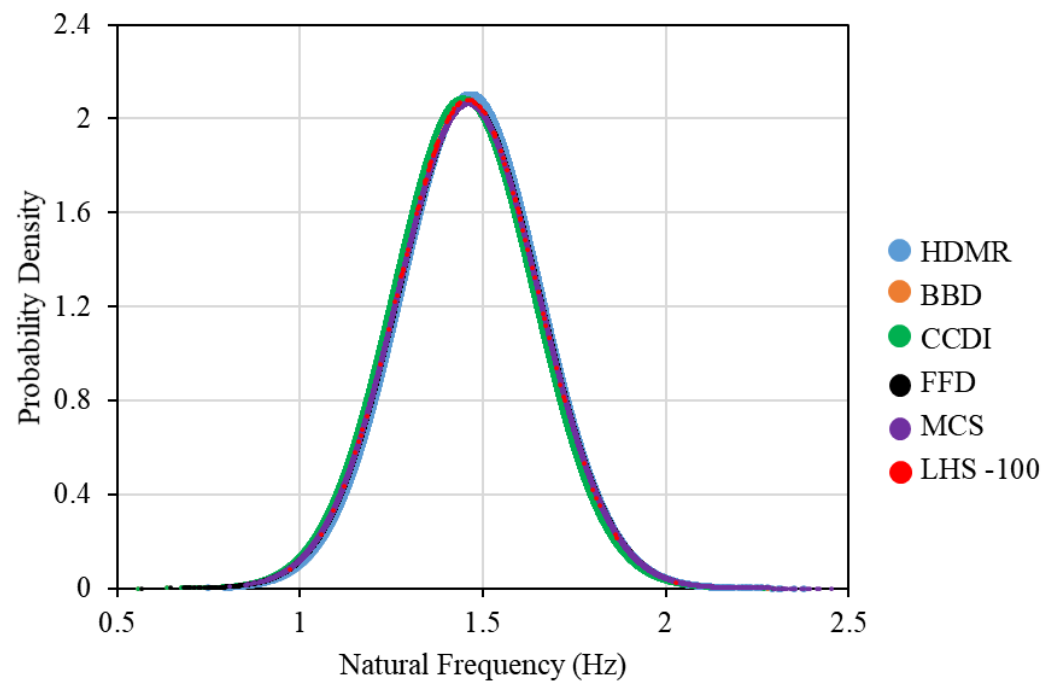

Figure 6. The probability distribution of natural frequencies obtained by different methods

\subsection{Effect of ignoring the less significant random variables on the output frequency}

It is found that the coefficients $a_{0}$ is comparatively smaller (less than unity) for $E_{\mathrm{c}}, W$ and $B_{w}$. However, values of $a_{1}$ and $a_{2}$ representing the metamodel for $W$ is considerably higher among the three variables. Hence, it can be inferred that the contribution of dispersion of $E_{\mathrm{c}}$ and $B_{w}$ to the output frequencies may not be very significant compared to that of other parameters. Therefore, the stochastic natural frequencies are re-calculated by all the metamodel methods, HDMR, CCD, $\mathrm{BBD}$ and FFD considering the mean values of $E_{\mathrm{c}}$ and $B_{w}$ and corresponding uncertainty of the remaining five random variables. The mean and standard deviation of the output frequency responses obtained are summarized in Table 6. The values in the parenthesis represent the mean frequencies and the standard deviation of the output frequencies estimated considering all seven random variables. Table 6 shows that there are no substantial changes in the output frequencies after ignoring the uncertainty of less significant random variables. Table 6 also supports the conclusions drawn earlier from the results with all seven random variables. It is to be noted here that the dispersions in the output natural frequencies are reduced with the reduction of number of input random variables as evident from the standard deviation values. The frequency responses obtained from all the metamodel methods, HDMR, CCD, BBD and FFD considering five significant random variables are compared with the corresponding values obtained by MCS in Figs. $7 \mathrm{a}, 7 \mathrm{~b}, 7 \mathrm{c}$, and $7 \mathrm{~d}$ respectively. 
Table 6. Statistical parameters of natural frequency considering five significant random variables

\begin{tabular}{|c|c|c|}
\hline Methods & Mean $(\mathrm{Hz})$ & Std. Dev. $(\mathrm{Hz})$ \\
\hline HDMR & $1.469(1.466)$ & $0.157(0.190)$ \\
\hline CCD & $1.450(1.446)$ & $0.159(0.191)$ \\
\hline BBD & $1.445(1.450)$ & $0.158(0.192)$ \\
\hline FFD & $1.465(1.461)$ & $0.159(0.193)$ \\
\hline MCS - 100,000 & $1.463(1.460)$ & $0.160(0.193)$ \\
\hline LHS -15 & $1.475(1.465)$ & $0.179(0.190)$ \\
\hline LHS - 100 & $1.467(1.459)$ & $0.174(0.192)$ \\
\hline
\end{tabular}

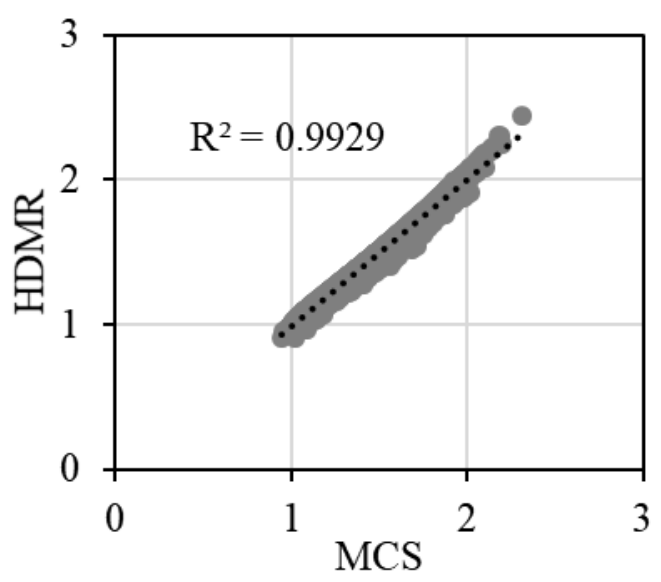

(a) HDMR

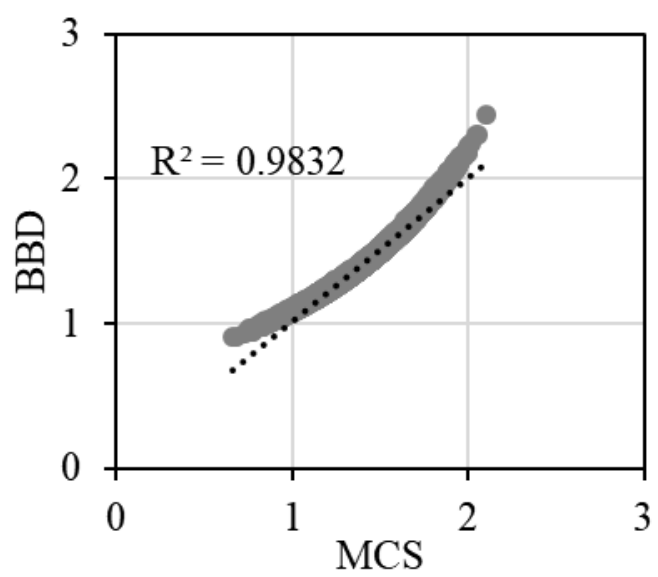

(c) BBD

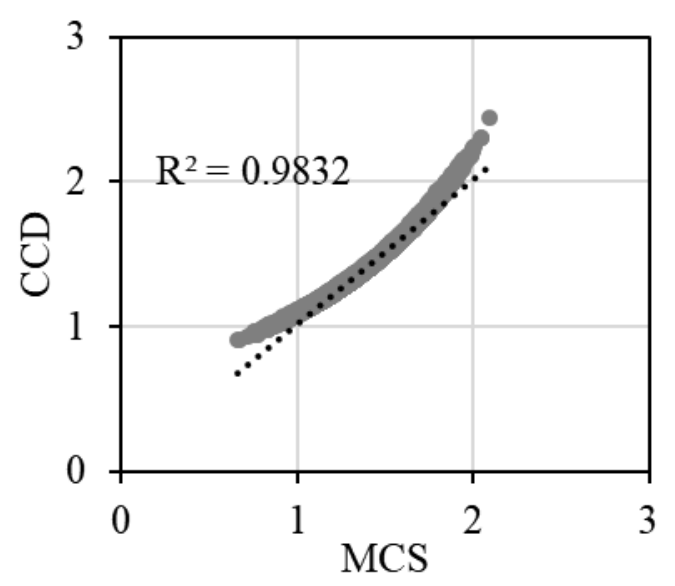

(b) $\mathrm{CCD}$

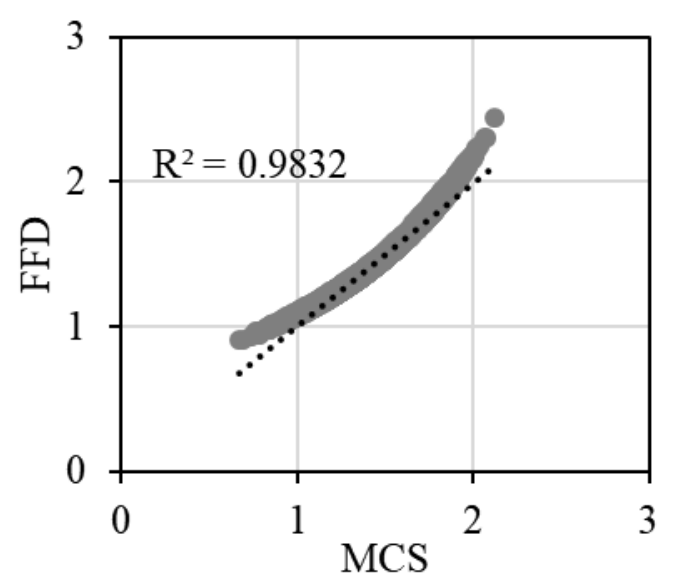

(d) FFD

Figure 7. Comparison of responses predicted by different metamodel methods considering five significant random variables with MCS. 
It can be seen that the HDMR method perform better compared to other methods as evident from the $\mathrm{R}^{2}$ values. The results ignoring the less significant parameters affects the random output frequencies only marginally. Therefore, it can be concluded that one can exclude the less significant parameters to reduce the computations without much loss of accuracy.

\section{NONLINEAR RESPONSE OF RC FRAME}

The response of an $\mathrm{RC}$ frame subjected to the earthquake force is random due to uncertainty in loading, material and geometric properties of the building frame. Various metamodel based approaches described in previous sections are used in this study to obtain stochastic time history response of the selected RC frame. Further, the seismic fragilities of the frame for various performance levels are computed using the selected metamodel-based approaches considering maximum inter-storey drift (ISD) as the damage parameter.

\subsection{Modeling of uncertainties and selection of ground motions}

The random variables representing the material properties of the building frame, concrete compressive strength $\left(f_{c}\right)$, yield strength of steel $\left(f_{y}\right)$ and damping $(\xi)$, are selected for this study and their statistical properties are tabulated in Table 7. Uncertainty in the seismic load is accounted in the study by taking PGA as a random variable. Twenty-two pairs of far-field natural ground motion records collected from published literature [47] are considered in this study for fragility analysis. These natural ground motions are scaled to match the design spectrum of Indian Standard [24] with PGAs ranging from $0.1 \mathrm{~g}$ to $1.0 \mathrm{~g}$ for non-linear time history analyses using a computer program WavGen [48].

Table 7. Random variables for stochastic nonlinear time history analysis of RC frame

\begin{tabular}{|l|c|c|l|c|}
\hline \multicolumn{1}{|c|}{ Random variables } & Mean & COV $(\%)$ & $\begin{array}{l}\text { Probability } \\
\text { distribution }\end{array}$ & Source \\
\hline $\begin{array}{l}\text { Concrete compressive } \\
\text { strength }\left(f_{c}\right)\end{array}$ & $33.66 \mathrm{MPa}$ & 21 & Normal & {$[49]$} \\
\hline Steel yield strength $\left(f_{y}\right)$ & $483.47 \mathrm{MPa}$ & 10 & Normal & {$[49]$} \\
\hline Global damping ratio $(\xi)$ & $5 \%$ & 76 & Lognormal & {$[34]$} \\
\hline
\end{tabular}




\subsection{Development of metamodel using HDMR}

In line with the free vibration example presented earlier, the metamodel expression is considered as a polynomial relationship between the input random variables $\left(f_{c}, f_{y}, \xi\right.$ and PGA) and the output ISD responses of the frame. Using Eq. (3), the metamodels for mean and standard deviation of the output response, ISD can be written in terms of individual metamodel functions of each random variables $\left(f_{c}, f_{y}, \xi\right.$ and $\left.\mathrm{PGA}\right)$ as:

$$
\begin{gathered}
I S D_{\mu}=f_{0}+f\left(f_{c}\right)+f\left(f_{y}\right)+f(\xi)+f(P G A) \\
I S D_{\sigma}=g_{0}+g\left(f_{c}\right)+g\left(f_{y}\right)+g(\xi)+g(P G A)
\end{gathered}
$$

The functions $f\left(f_{c}\right), f\left(f_{y}\right) \quad f(\xi)$ and $f(P G A)$ in Eq. (9) and others in Eq. (10) are assumed to be quadratic functions as given in Eq. (8) with coefficients, $a_{0}, a_{1}$ and $a_{2}$. The solution of three unknown coefficients, $a_{0}, a_{1}$ and $a_{2}$, in the assumed quadratic functions require three equations for each random variable. The left-hand side of the Eq. (8) shall be obtained from the output response at the sampling points (represented by the combination of all input variables as per the chosen metamodel method) by conducting finite element analyses. The total number of sampling points required in the HDMR method depends on the number $(n)$ of random variables, which is four $\left(f_{c}, f_{y}, \xi\right.$ and PGA) in this example. Therefore, the total number of sampling points for the solution of unknown coefficients for all the random variables are nine $(2 n+1=9)$. The nine sampling points are selected as per the scheme explained in Fig. 1. The values of input variables (considered at the sampling points) and the combinations of the input variables at the sampling points are as shown in Table 8 and 9 , respectively.

Table 8. Input variables used in 3-point sampling in HDMR

\begin{tabular}{|c|c|c|c|}
\hline Variable & $\mu-\sigma$ & $\mu$ & $\mu+\sigma$ \\
\hline$f_{c}(\mathrm{MPa})$ & 26.59 & 33.66 & 40.73 \\
\hline$f_{y}(\mathrm{MPa})$ & 435.13 & 483.48 & 531.82 \\
\hline$\xi(\%)$ & 1.2 & 5.0 & 8.8 \\
\hline PGA $(\mathrm{g})$ & 0.10 & 0.55 & 1.00 \\
\hline
\end{tabular}

( $\mu$ and $\sigma$ are mean and standard deviation of the random variables) 
It can be seen from Table 8 that $f_{c}, f_{y}$ and $\xi$ are random variables representing the characteristics of the building frame and the variable, PGA denotes the peak value of the acceleration of the ground motions.

Table 9. Random variables at sampling points in HDMR method and FEA analysis

\begin{tabular}{|c|c|c|c|c|c|c|}
\hline S1. No & $f_{c}(\mathrm{MPa})$ & $f_{y}(\mathrm{MPa})$ & $\xi(\%)$ & $P G A(\mathrm{~g})$ & $I S D_{\mu}(\%)$ & $I S D_{\sigma}(\%)$ \\
\hline 1 & 33.66 & 483.48 & 5.0 & 0.55 & 2.35 & 1.24 \\
\hline 2 & 40.73 & 483.48 & 5.0 & 0.55 & 2.26 & 1.23 \\
\hline 3 & 26.59 & 483.48 & 5.0 & 0.55 & 2.47 & 1.26 \\
\hline 4 & 33.66 & 531.82 & 5.0 & 0.55 & 2.35 & 1.23 \\
\hline 5 & 33.66 & 435.13 & 5.0 & 0.55 & 2.35 & 1.26 \\
\hline 6 & 33.66 & 483.48 & 1.2 & 0.55 & 3.17 & 1.74 \\
\hline 7 & 33.66 & 483.48 & 8.8 & 0.55 & 1.91 & 0.99 \\
\hline 8 & 33.66 & 483.48 & 5.0 & 1.00 & 5.03 & 2.65 \\
\hline 9 & 33.66 & 483.48 & 5.0 & 0.10 & 0.35 & 0.14 \\
\hline
\end{tabular}

The computational models (at sampling points) of the building corresponding to the first three random variables $\left(f_{c}, f_{y}\right.$ and $\left.\xi\right)$ are developed to conduct nonlinear time history analyses using selected 22 pairs of ground motions. Mean $\left(I S D_{\mu}\right)$ and standard deviation $\left(I S D_{\sigma}\right)$ of the ISD responses for each computational model are recorded. The unknown coefficients for input random variables (refer to Eq. 8) are obtained using the nonlinear time history results, and HDMR metamodels for $I S D_{\mu}$ and $I S D_{\sigma}$ are developed. Overall metamodel that represents the stochastic ISD response is expressed by combining the metamodels for $I S D_{\mu}$ and $I S D_{\sigma}$ as:

$$
I S D=I S D_{\mu}+N\left[0, I S D_{\sigma}\right]
$$

Where $I S D=$ Maximum inter-storey drift obtained from the overall metamodel, $I S D_{\mu}=$ Metamodel representing mean of the inter-storey drift (Eq. 9), $I S D_{\sigma}=$ Metamodel representing the standard deviation of the inter-storey drift (Eq. 10) and $N\left[0, I S D_{\sigma}\right]=$ Normal probability distribution with mean zero and standard deviation, ISD $D_{\sigma}$. The coefficients $\left(\mathrm{a}_{0}, \mathrm{a}_{1}\right.$, and $\left.\mathrm{a}_{2}\right)$ computed for each random variable to form the overall metamodel is presented in Table 10. 


\subsection{Development of metamodel using CCD and BBD methods}

The input random variables are sampled to construct the metamodel for other response surface methods (CCD and $\mathrm{BBD}$ ) as per the corresponding DOE technique. The general metamodel relationship connecting the input random variables and output ISD can be obtained by considering the linear and quadratic terms (neglecting the effect of interaction terms of the random variables) from Eq. (2).

Table 10. Coefficients of input random variables for HDMR metamodel

\begin{tabular}{|c|c|c|c|c|c|}
\hline \multicolumn{2}{|c|}{ Metamodel coefficients } & $f_{c}$ & $f_{y}$ & $\xi$ & $P G A$ \\
\hline \multirow{3}{*}{ For $I S D_{\mu}$} & $\mathrm{a}_{0}$ & 0.922 & 0.200 & 1.157 & -2.355 \\
\cline { 2 - 6 } & $\mathrm{a}_{1}$ & -0.040 & -0.001 & -29.752 & 3.363 \\
\cline { 2 - 6 } & $\mathrm{a}_{2}$ & 0.0004 & 0.0000 & 132.1000 & 1.6702 \\
\hline \multirow{4}{*}{ For $I S D_{\sigma}$} & $\mathrm{a}_{0}$ & 0.264 & 0.588 & 0.710 & -1.305 \\
\cline { 2 - 6 } & $\mathrm{a}_{1}$ & -0.013 & -0.002 & -18.512 & 1.953 \\
\cline { 2 - 6 } & $\mathrm{a}_{2}$ & 0.0002 & 0.0000 & 86.2340 & 0.7648 \\
\hline
\end{tabular}

The metamodels for mean and standard deviation of ISD can be expressed as given in Eq. (12) and Eq. (13).

$$
\begin{array}{r}
I S D_{\mu}=\beta_{0}+\beta_{1} f_{c}+\beta_{2} f_{y}+\beta_{3} \xi+\beta_{4} P G A+\beta_{11} f_{c}^{2}+\beta_{22} f_{y}^{2}+\beta_{33} \xi^{2}+\beta_{44} P G A^{2} \\
I S D_{\sigma}=\gamma_{0}+\gamma_{1} f_{c}+\gamma_{2} f_{y}+\gamma_{3} \xi+\gamma_{4} P G A+\gamma_{11} f_{c}^{2}+\gamma_{22} f_{y}^{2}+\gamma_{33} \xi^{2}+\gamma_{44} P G A^{2}
\end{array}
$$

The coefficients of these metamodel relationships are found out in this study using conventional DOE methods.

The accuracy of the metamodel expressions can be studied by comparing the output ISD values predicted by different metamodel methods with those obtained from nonlinear time history analysis at sampling points as presented in the Figs. $8 \mathrm{a}, 8 \mathrm{~b}$, and $8 \mathrm{c}$ respectively for HDMR, CCD, and BBD. $\mathrm{R}^{2}$ values show that the HDMR method predicts ISD response more accurately in comparison with other metamodel methods (CCD and BBD). 


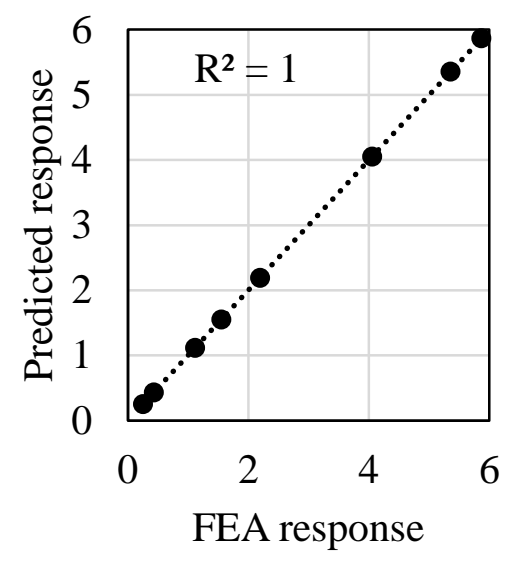

(a) HDMR

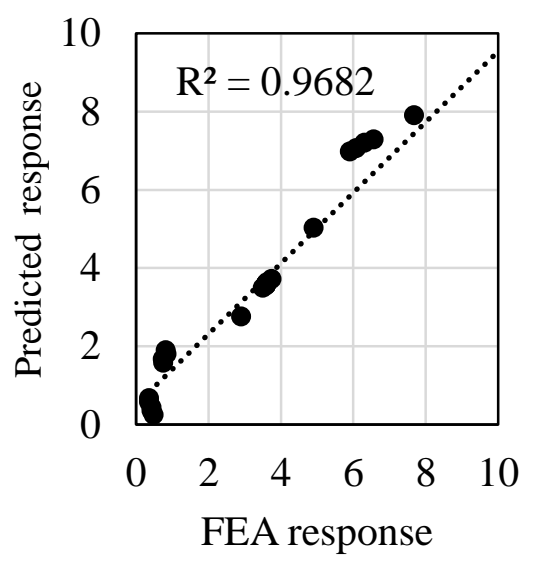

(b) $\mathrm{CCD}$

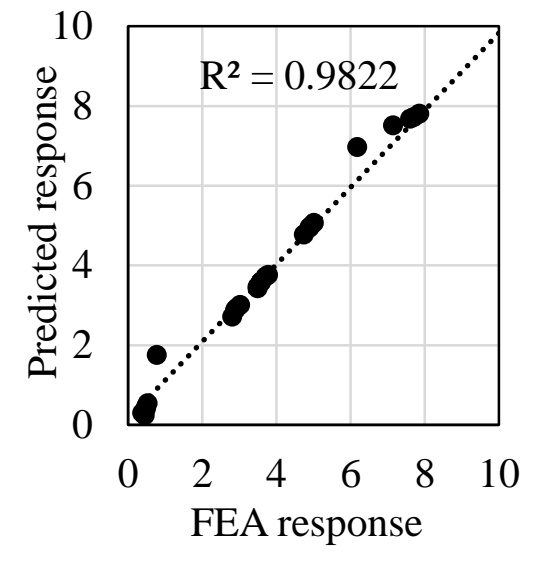

(c) BBD

Figure 8. Comparison of ISD ratio (\%) responses obtained from different metamodels with FEA.

\subsection{Comparison of probability distributions of ISD}

In order to understand the effectiveness of HDMR method over the conventional metamodel methods, a comparison of the probability distribution of simulated ISD values from HDMR, CCD and BBD are presented in Fig 9. The probability distributions of ISD responses from the three methods (HDMR, CCD and BBD) are found to be overlapping.

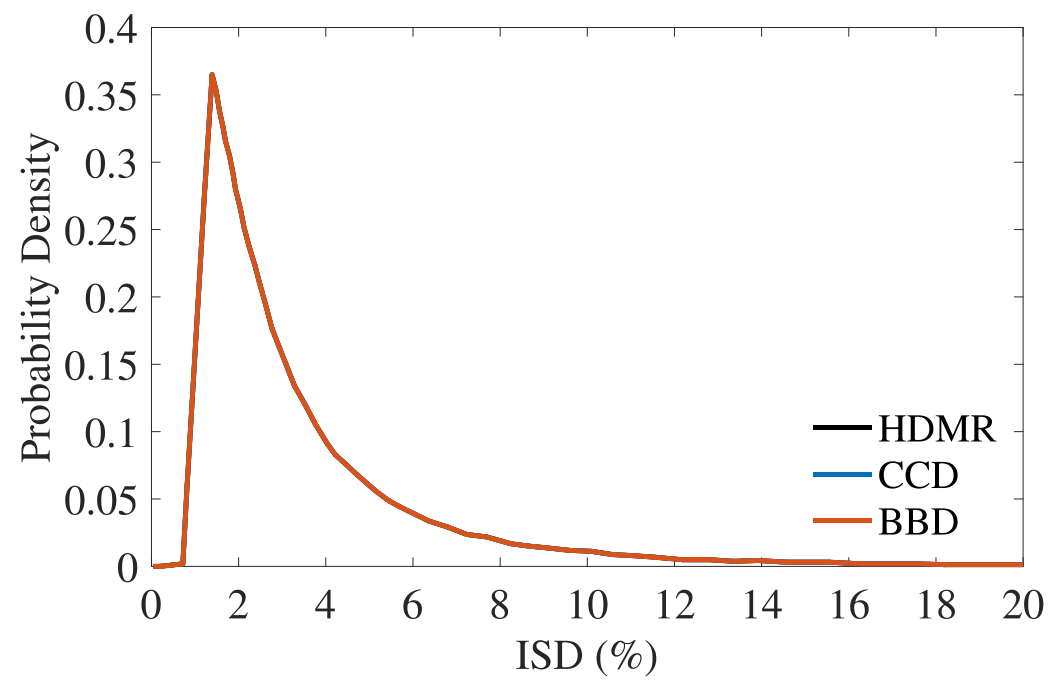

Figure 9. Comparison of probability distributions of ISD responses 
The mean and standard deviation of the ISD responses and the number of nonlinear time history analysis required for developing the metamodel in each method are presented in Table 11. Table 11 shows that the HDMR metamodel method requires nonlinear time history analyses only at nine set of sampling points in comparison with 37 for CCD and 28 for BBD. However, mean and standard deviations of ISD responses obtained from three selected methods do not differ significantly. This means that the three methods could predict the ISD responses with the similar accuracy although HDMR method needs less number of sampling points compared to others.

Table 11. Comparison of ISD responses obtained from different methods

\begin{tabular}{|c|c|c|c|}
\hline Method & Mean (\%) & $\begin{array}{c}\text { Standard deviation } \\
(\%)\end{array}$ & $\begin{array}{c}\text { Number of sample } \\
\text { points required }\end{array}$ \\
\hline HDMR & 2.63 & 2.09 & 9 \\
\hline CCD & 2.61 & 2.12 & 37 \\
\hline BBD & 2.66 & 2.17 & 28 \\
\hline
\end{tabular}

\section{FRAGILITY CURVES USING DIFFERENT METAMODEL BASED METHODS}

A fragility function represents the probability of $I S D$ exceeding a selected performance level at a specific intensity level. Fragility curve presents a cumulative probability distribution which indicates the probability that a building will be damaged to a given damage state or a more severe one, as a function of intensity level. Many previous studies use nonlinear dynamic analyses to develop the fragility curves of RC structures using a closed form equation [50-52]. However, metamodel based approaches, HDMR, CCD, and BBD are used to develop the fragility curves for various performance limit states in this study. The limit states corresponding to various performance levels required for the fragility analysis are taken from standard guidelines [53] and presented in Table 11.

Table 11. ISD limits associated with various structural performance levels

\begin{tabular}{|l|c|}
\hline Performance level & ISD $(\%)$ \\
\hline Immediate Occupancy (IO) & 1 \\
\hline Life Safety (LS) & 2 \\
\hline Collapse Prevention (CP) & 4 \\
\hline
\end{tabular}




\subsection{Convergence studies}

The number of simulations required to produce a reasonably accurate and consistent estimation of the probability of exceedance using various metamodel based approaches (HDMR, $\mathrm{CCD}$, and $\mathrm{BBD})$ is determined by carrying out a convergence study. A specific value of PGA of $0.55 \mathrm{~g}$ is selected as the intensity measure, and the number of simulations of the metamodel is varied from 10 to 100,000 to obtain the probability of exceedance at CP limit state. The variation of the probabilities of exceedance with the number of simulations is presented in Fig. 10. It is found that the number of simulations required to yield reasonably good converged estimation of the probability of exceedance is about 100,000 . The same number of simulations are considered further to obtain the fragility curves.

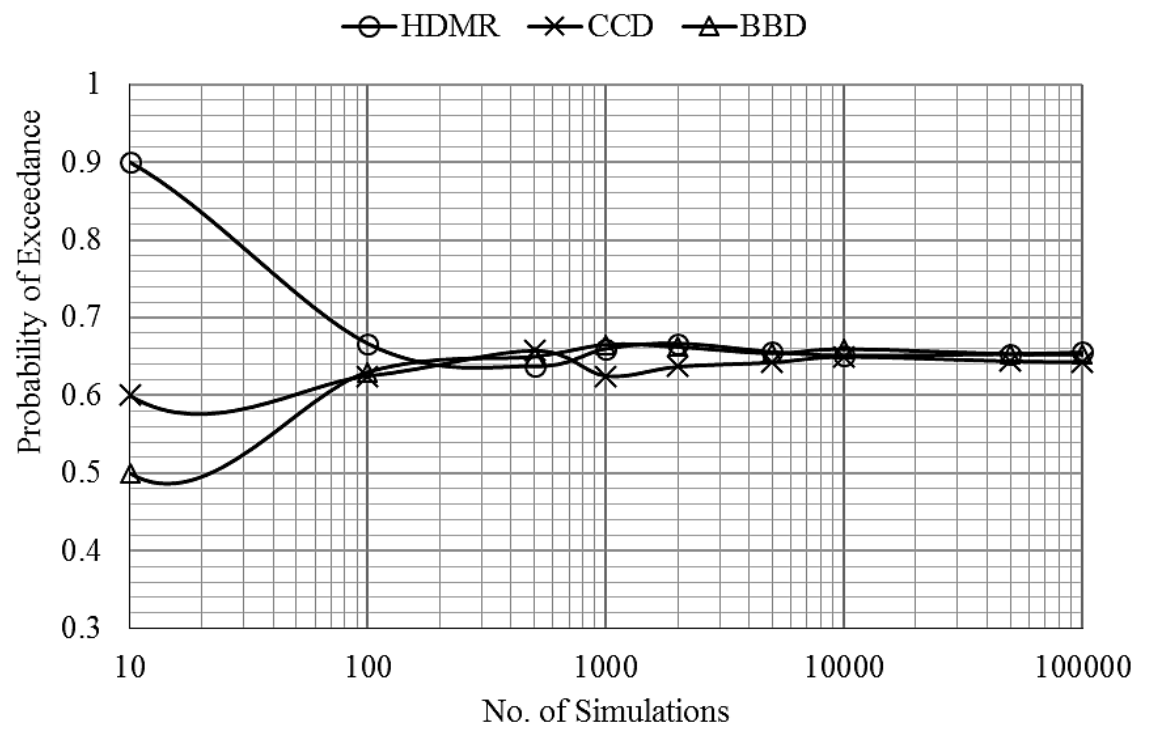

Figure 10. Convergence study for various metamodel methods.

\subsection{Fragility curves using selected Metamodels}

The mean and standard deviation of the output responses in each metamodel method (HDMR, CCD, and BBD) are expressed in terms of the input random variables as per the assumed metamodel. The values of input variables are randomly generated using MCS based on their respective probability distributions to obtain corresponding output ISD responses. 100,000 number of simulations are conducted for each PGA level, and the number of simulations with ISD responses exceeding each of the performance limit states, IO, LS, and CP are found out. This is 
expressed as a fraction of the total number of simulations at each PGA to obtain the exceedance probability at each limit state. Accordingly, the fragility functions are obtained for selected PGA using each metamodel approaches. Comparison of fragility curves obtained from each metamodel method is presented in Figs. 11, 12 and 13 respectively for the IO, LS and CP performance limit states. The fragility curves developed using the three methods (HDMR, CCD, and BBD) are found to overlap, which indicates that the three methods could predict the ISD responses almost with the same accuracy, while HDMR method takes less number of sampling points and computations compared to others.

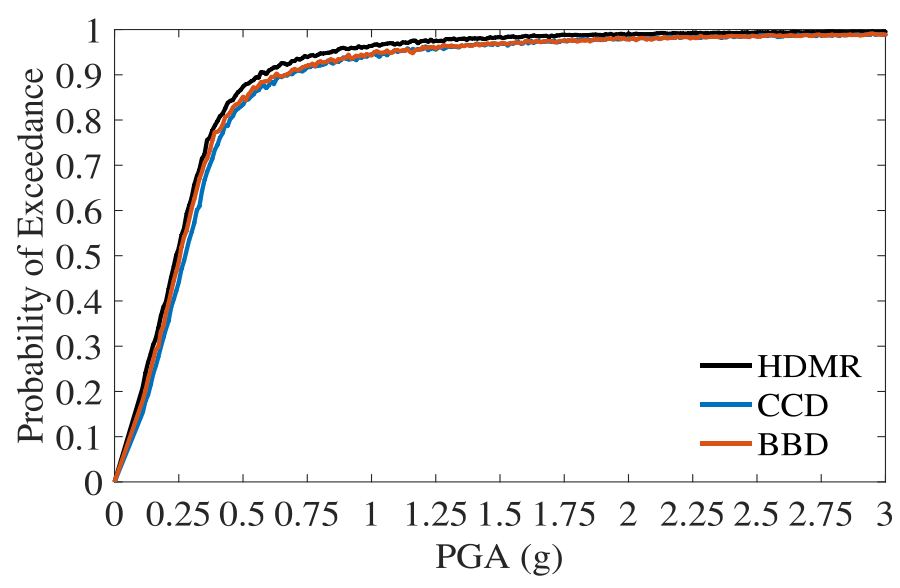

Figure 11. Fragility curves for IO limit state.

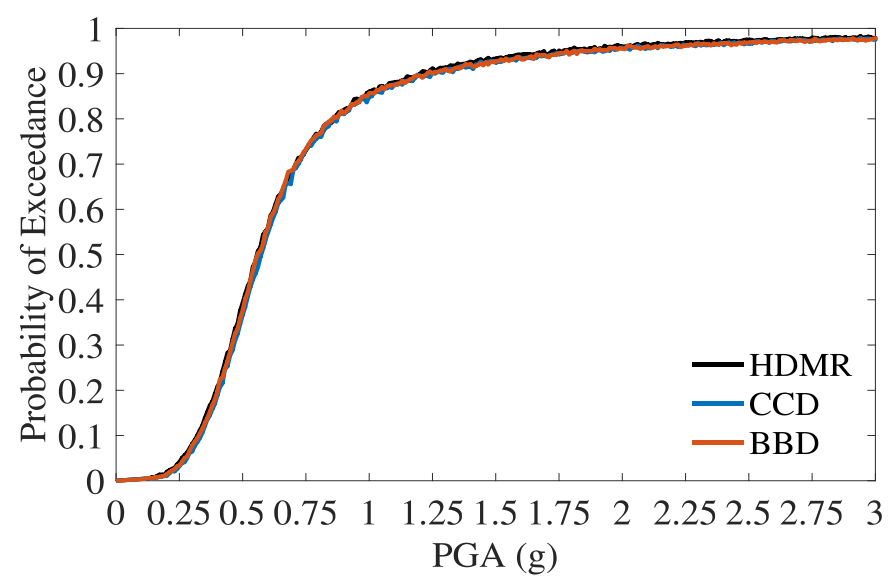

Figure 12. Fragility curves for LS limit state. 


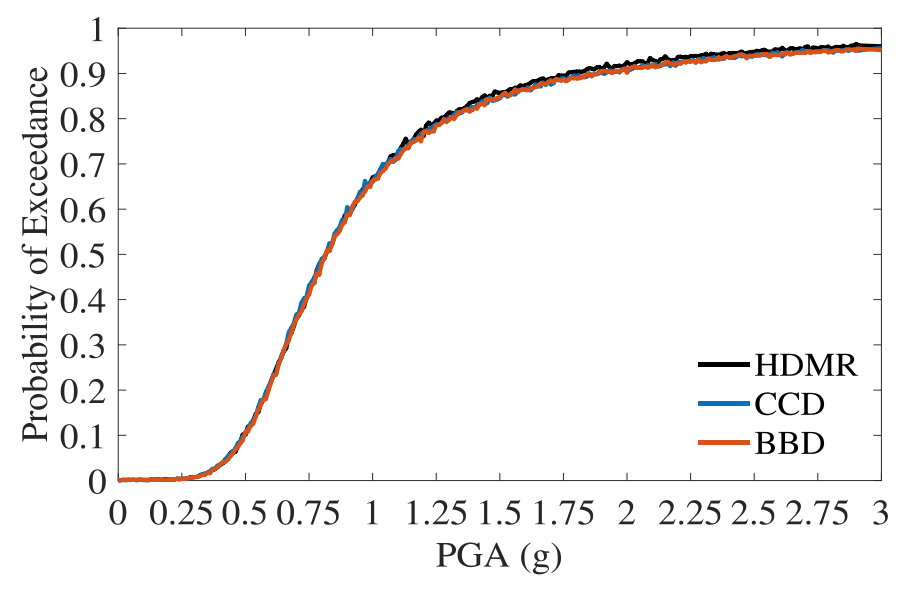

Figure 13. Fragility curves for CP limit state.

Once the metamodel is obtained in the HDMR method, further FEA of the computational model can be eliminated, which is an advantage of metamodel-based methods. Out of all other metamodel-based methods, HDMR is found to be more effective with less computation. It is to be noted that the fragility curves developed in this study assume a deterministic value of limit state capacity. However, uncertainties may exist in the limit state capacity [54], which can be incorporated by considering the limit state capacity as a random variable. The formulation of response surface (using HDMR, CCD, and $\mathrm{BBD}$ ) metamodel expression and its simulation, incorporating the limit state capacity as a random variable is possible for the development of fragility curves. This process requires only the statistical properties of the limit state capacity. Therefore, the metamodel method is more convenient for this purpose than other methods of evaluating the fragility curves.

\section{Conclusions}

Randomness exists in the responses of reinforced concrete structures due to the uncertainties in geometry, material properties, and loading. A stochastic analysis incorporating the uncertainties in the input properties is essential to study the random dynamic responses. Statistical or non-statistical approaches can be employed to conduct such stochastic analysis. Monte Carlo Simulation is an accurate statistical method for stochastic analysis. Non-statistical approaches based on metamodel concepts have been reported as an alternative to computationally intensive 
statistical approaches. The present study explores the application of non-statistical high dimensional model representation (HDMR) metamodel for the dynamic analysis of buildings. The effectiveness of non-statistical HDMR is evaluated in the current study by comparing its results with those of the traditional approaches such as response surface method using the design of experiments (DOE). For this purpose, the current study selected typical RC building with material and geometric uncertainties. Salient conclusions noted from the case studies are as follows.

- HDMR method found to yield output responses with similar accuracy with lowest computational effort compared to other metamodel-based approaches for both the examples considered in this study.

- The results show that the insignificant random parameters can be excluded from the analysis using HDMR metamodel to reduce the computational effort further without much loss of accuracy.

- This paper attempted to use the HDMR metamodel approach for the first time to develop seismic fragility curves of RC framed buildings. This approach is found to be promising as it involves much lesser computation compared to other traditional methods.

Although the results are deduced based on the selected case studies, the methodology is applicable and relevant to other structures also. The significance of the HDMR lies in the less number of sampling points compared to the traditional response surface methods. 


\section{REFERENCES}

1. Xu J, Chen J, Li J. Probability density evolution analysis of engineering structures via cubature points. Computational Mechanics 2012;50(1):135-156.

2. Rubinstein RY, Kroese DP. Simulation and the Monte Carlo method. John Wiley and Sons Inc. New York, 1981.

3. Stein M. Large sample properties of simulations using Latin hypercube sampling. Technometrics 1987 May 1;29(2):143-51.

4. Ericson WA. Optimum stratified sampling using prior information. Journal of the American Statistical Association 1965 Sep 1;60(311):750-71.

5. Chakraborty S, Mandal B, Chowdhury R, Chakrabarti A. Stochastic free vibration analysis of laminated composite plates using polynomial correlated function expansion. Composite Structures 2016;135:236-249.

6. Cardoso JB, de Almeida JR, Dias JM, Coelho PG. Structural reliability analysis using Monte Carlo simulation and neural networks. Advances in Engineering Software 2008 Jun 30;39(6):505-13.

7. Mangalathu S. Performance based grouping and fragility analysis of box-girder bridges in California, Ph.D. Thesis, Georgia Tech, 2017.

8. Bucher C, Bourgund U. A fast and efficient response surface approach for structural reliability problems. Structural Safety 1990;7(1):57-66.

9. Box GEP, Wilson KB. On the experimental attainment of optimum conditions. Journal of the Royal Statistical Society. Series B (Methodological). 1951;13(1):1-45.

10. Box GE, Behnken DW. Some new three level designs for the study of quantitative variables. Technometrics 1960;2(4):455-475.

11. Franchin P, Lupoi A, Pinto PE, Schotanus MI. Seismic fragility of reinforced concrete structures using a response surface approach. Journal of Earthquake Engineering 2003;7:4577.

12. Buratti N, Ferracuti B, Savoia M. Response surface with random factors for seismic fragility of reinforced concrete frames. Structural Safety 2010;32(1):42-51. 
13. Seo J, Dueas-Osorio L, Craig JI, Goodno BJ. Metamodel-based regional vulnerability estimate of irregular steel moment-frame structures subjected to earthquake events. Engineering Structures 2012;45:585-597.

14. Seo J, Linzell DG. (2013). Use of response surface metamodels to generate system level fragilities for existing curved steel bridges. Engineering Structures 2013;52:642-653.

15. Park J, Towashiraporn P. Rapid seismic damage assessment of railway bridges using the response-surface statistical model. Structural Safety 2014;47:1-12.

16. Rabitz H, Mer FA, Shorter J, Shim K. Efficient input output model representations. Computer Physics Communications 1999;117(12):11-20.

17. Chowdhury R, Rao BN, Prasad AM. High-dimensional model representation for structural reliability analysis. Communications in Numerical Methods in Engineering 2009;25(4):301337.

18. Unnikrishnan VU, Prasad AM, Rao BN. Development of fragility curves using highdimensional model representation. Earthquake Engineering and Structural Dynamics 2013;42(3):419-430.

19. Towashiraporn P. Building seismic fragilities using response surface metamodels. Ph.D. thesis, Georgia Institute of Technology, August 2004.

20. Montgomery DC. Design and Analysis of Experiments. John Wiley and Sons, Inc., New York, 2004.

21. Wu CFJ, Hamada M. Experiments Planning, Analysis, and Parameter Design Optimization. John Wiley and Sons, Inc., New York; 2000.

22. Pragalath DH, Bhosale A, Davis R., Sarkar P. Multiplication factors for open ground storey buildings - A reliability based evaluation, Earthquake Engineering and Engineering Vibration 2016; 15(2): 283-295.

23. IS 456. Indian Standard Plain and Reinforced Concrete-Code of Practice. Bureau of Indian Standards, New Delhi; 2000.

24. IS 1893. Indian standard criteria for earthquake resistant design of structures. Bureau of Indian Standards, New Delhi, India; 2016. 
25. IS 13920. Indian standard ductile detailing of reinforced concrete structures subjected to seismic forces. Bureau of Indian Standards, New Delhi, India, 2016.

26. Mazzoni S, Mckenna F, Scott MH, Fenves GL. The Open System for Earthquake Engineering Simulation (OpenSEES) User Command-Language Manual, 2006.

27. Kent D, and Park R. Flexural members with confined concrete, Journal of the Structural Division, 1971; 97(ST7): 1969-1990.

28. Filippou FC, Popov EP, Bertero VV. Effects of bond deterioration on hysteretic behavior of reinforced concrete joints, Report EERC 83-19, Earthquake Engineering Research Center, University of California, Berkeley, 1983.

29. Bhosale A, Davis R, Sarkar P. Sensitivity and Reliability Analysis of Masonry Infilled Frames. World Academy of Science, Engineering, and Technology, International Journal of Civil, Environmental, Structural, Construction and Architectural Engineering 2016 Oct $1 ; 10(12): 1508-12$.

30. Celarec D, Dolsek M, The impact of modelling uncertainties on the seismic performance assessment of reinforced concrete frame buildings", Engineering Structures 2013;52:340-354.

31. Iman RL, Conover WJ. Small sample sensitivity analysis techniques for computer models with an application to risk assessment. Communications in statistics-theory and methods 1980 Jan 1;9(17):1749-842.

32. Iman RL, Helton, JC, Campbell JE. An Approach to Sensitivity Analysis of Computer Models, Part 1, Journal of Quality Technology 1981;13(3):174-183.

33. Iman RL, Helton JC, Campbell JE. An Approach to Sensitivity Analysis of Computer Models, Part 2, Journal of Quality Technology 1981;13(4):232-240.

34. Kim JH, Choi I, Park J. Uncertainty analysis of system fragility for seismic safety evaluation of NPP, Nuclear Engineering and Design 2010;241(7):2570-2579.

35. Kwon OS, Elnashai AS. The effect of material and ground motion uncertainty on the seismic vulnerability curves of RC structure, Engineering Structures 2006;28:289-303. 
36. Kwon OS, Elnashai AS. Sensitivity of Analytical Vulnerability Functions to Input and Response Parameter Randomness, Proceedings of 13th World Conference on Earthquake Engineering, Vancouver, Canada, 2004.

37. Lee TH, Mosalam K.M. Sensitivity of seismic demand of a reinforced concrete shear-wall building, Applications of Statistics and Probability in Civil Engineering 2003;1511-1518.

38. Mitropoulou CC, Lagaros ND, Papadrakakis M. Life-cycle cost assessment of optimally designed reinforced concrete buildings under seismic actions, Reliability Engineering and System Safety 2011;96(10):1311-1331.

39. Panandikar N, Babunarayan KS. Sensitivity of Pushover Curve to Material and Geometric Modelling-An Analytical Investigation, ISTRUC-19 2015;21:91-97.

40. Porter KA, Beck JL, Shaikhutdinov RV. Sensitivity of Building Loss Estimates to Major Uncertain Variables. Earthquake Spectra 2002;18(4):719-743.

41. Singhal A, Kiremidjian AS. Method for probabilistic evaluation of seismic structural damage, Journal of Structural Engineering 1996;122(12):1459-1467.

42. Val D, Bljuger F, Yankelevsky D. Reliability evaluation in nonlinear analysis of reinforced concrete structures. Structural Safety 1997;19(2):203-217.

43. Ау BÖ. Fragility based assessment of low-rise and mid-rise reinforced concrete frame buildings in Turkey. M.S. Thesis, Middle East Technical University, Turkey, 2008.

44. Nowak AS, Collins KR. Reliability of Structures, McGraw-Hill Companies, Inc., New York, 2000

45. Ellingwood B. Development of a probability based load criterion for American National Standard A58: Building code requirements for minimum design loads in buildings and other structures. US Department of Commerce, National Bureau of Standards; 1980.

46. Bal IE, Crowley H, Pinho R. Detail assessment of structural characteristics of Turkish RC buildings stock for loss assessment models. Soil Dynamic and Earthquake Engineering 2008;28:914-932.

47. FEMA P695. Quantification of Building Seismic Performance Factors. Applied Technology Council, Redwood City: California, 2012. 
48. Mukherjee S, Gupta VK. Wavelet-based generation of spectrum-compatible time-histories. Soil Dynamics and Earthquake Engineering 2002 Oct 1;22(9-12):799-804.

49. Ranganathan R. Reliability Analysis and Design of Structures. Tata McGraw-Hill, New Delhi; 1990.

50. Cornell CA, Jalayer F, Hamburger RO, Foutch DA. Probabilistic basis for 2000 SAC Federal Emergency Management Agency steel moment frame guidelines. Journal of Structural Engineering 2002;128(4):526-533.

51. Mangalathu S, Jeon JS, Padgett JE, DesRoches R. ANCOVA-based grouping of bridge classes for seismic fragility assessment. Engineering Structures. 2016 Sep 15;123:379-94.

52. Mangalathu S, Jeon J, DesRoches R, Padgett JE. Analysis of Covariance to Capture the importance of bridge attributes on the probabilistic seismic demand model. InProc. 15th Pacific Conference on Earthquake Engineering, Sydney, 2015.

53. ASCE/SEI 41-06. Seismic Rehabilitation of Existing Buildings. American Society of Civil Engineers, Reston, VA, USA, 2007.

54. Аy BÖ, Erberik MA. Vulnerability of Turkish low-rise and mid-rise reinforced concrete frame structures. Journal of Earthquake Engineering. 2008 May 14;12(S2):2-11. 